\title{
Reducing Hardware-Related Complications of Deep Brain Stimulation
}

\author{
Constantine Constantoyannis, Caglar Berk, Christopher R. Honey, Ivar Mendez, \\ Robert M. Brownstone
}

\begin{abstract}
Background: Deep brain stimulation (DBS) is used increasingly worldwide for the treatment of Parkinson's disease, dystonia, tremor and pain. As with any implanted system, however, DBS introduces a new series of problems related to its hardware. Infection, malfunction and lead migration or fracture may increase patient morbidity and should be considered when evaluating the risk/benefit ratio of this therapy. This work highlights several factors felt to increase DBS hardware complications. Methods: The authors undertook a prospective analysis of their patients receiving this therapy in two Canadian centres, over a four-year period. Results: One hundred and forty-four patients received 204 permanent electrode implants. The average follow-up duration was 24 months. Complications related to the DBS hardware were seen in 11 patients (7.6\%). There were two lead fractures $(1.4 \%)$ and nine infections $(6.2 \%)$ including two erosions $(1.4 \%)$. There was a significantly greater risk of infection in patients who underwent staged procedures with externalization. In patients with straight scalp incisions, the rate of infection was higher than that seen with curved incisions. Conclusion: Hardware complications were not common. A period of externalization of the electrodes for a stimulation trial was associated with an increased infection rate. It is also possible that a straight scalp incision instead of curvilinear incision may lead to an increase in the rate of infection. With a clear understanding of the accepted DBS device indications and their potential complications, patients may make a truly informed decision about DBS technology.
\end{abstract}

RÉSUMÉ: Réduire les complications dues à l'appareillage dans la stimulation cérébrale profonde. Introduction: La stimulation cérébrale profonde (SCP) est de plus en plus utilisée à travers le monde dans le traitement de la maladie de Parkinson, de la dystonie, du tremblement et de la douleur. Comme dans tout système comportant un implant, la SCP donne lieu à une nouvelle problématique reliée à l'appareillage utilisé. L'infection, le mauvais fonctionnement et le déplacement des électrodes ou leur fracture peut augmenter la morbidité. On devrait tenir compte de ces facteurs quand on évalue le rapport risques/bénéfices de ce traitement. Cette étude souligne plusieurs facteurs qui augmentent les complications de la SCP dues à l'appareillage. Méthodes: Les auteurs ont effectué une analyse prospective de leurs patients qui recevaient ce traitement dans deux centres canadiens au cours d'une période de quatre ans. Résultats: Cent quarante-quatre patients ont reçu 204 implants d'électrodes permanentes. La durée moyenne du suivi a été de 24 mois. On a observé des complications dues à l'appareillage utilisé pour la SCP chez 11 patients $(7,6 \%)$, dont deux fractures d'électrodes (1,4\%) et neuf infections $(6,2 \%)$ incluant deux érosions $(1,4 \%)$. Le risque d'infection était significativement supérieur pour les patients chez qui l'implantation était faite par étapes avec externalisation. Le taux d'infection était plus élevé chez les patients qui avaient subi une incision rectiligne du cuir chevelu par rapport à ceux dont l'incision était incurvée. Conclusion: Les complications dues à l'appareillage n'étaient pas fréquentes. Une période d'externalisation des électrodes pour procéder à un essai de stimulation était associée à un taux d'infection plus élevé. Il est également possible qu'une incision rectiligne du cuir chevelu plutôt qu'une incision courbe puisse augmenter le taux d'infection. Les patients peuvent prendre une décision vraiment éclairée s'ils comprennent les indications et les complications possibles de la SCP.

Can. J. Neurol. Sci. 2005; 32: 194-200

During the last decade many new options have become available for the surgical treatment of movement disorders. The development of new technologies for implanting chronic stimulating electrodes has made deep brain stimulation (DBS) a viable option to surgical lesioning. Unlike lesions which are permanent, DBS may be reversible and titratable. Deep brain stimulation has been demonstrated to be very effective and is increasingly used worldwide for the treatment of Parkinson's disease, dystonia, tremor and pain. ${ }^{1-5}$ As with any implanted system, however, DBS introduces a new series of problems related to its hardware. Infection, malfunction and lead migration or fracture may increase patient morbidity and should be considered when evaluating the risk/benefit ratio of this therapy.

From the Divisions of Neurosurgery at the University of British Columbia (CC, CRH); Vancouver and Dalhousie University (CB, IM, RMB); Halifax, Canada.

RECEIVED MAY 3, 2004. ACCEPTED IN FINAL FORM OCTOBER 14, 2004.

Reprint requests to: Christopher Honey, Division of Neurosurgery, Suite 325, 700 West 10th Avenue, Vancouver, BC, Canada V5Z 4E5 
In an attempt to identify and potentially reduce factors leading to hardware related DBS complications, the authors undertook a prospective analysis of their patients receiving this therapy over a four-year period. This work highlights several factors felt to increase DBS hardware complications and outlines treatment strategies.

\section{Patients and Methods}

A prospective, collaborative study of all DBS operations performed at the Surgical Centre for Movement Disorders in Vancouver and Queen Elizabeth II Hospital in Halifax was conducted from January 1999 to January 2003. The Surgical Centre for Movement Disorders is the tertiary neurosurgical referral centre for all DBS surgery in the Province of British Columbia (4 million people). The Queen Elizabeth II Hospital is the tertiary neurosurgical referral centre for all DBS surgery in Atlantic Canada ( $>2$ million people). Three different surgeons performed the operations.

One hundred and forty-five patients diagnosed with Parkinson's disease, dystonia, tremor or pain, underwent DBS electrode implantation. One patient did not obtain tremor control during the stimulation trial and the DBS electrode was removed. The remaining 144 patients were included in the study. Demographic data were collected including age, sex, diagnosis, coexisting diseases, previous neurosurgical operations and tobacco use. Several pre- and intraoperative variables were recorded, including the use of antibiotics, the type of scalp incision (straight or curvilinear), the length of the procedure and whether a stimulation trial with electrode externalization was used prior to internalization. The complications related to the DBS hardware were recorded. These included lead fracture, lead dislodgement, infection (including organism), DBS malfunction, allergic reaction to the hardware, subcutaneous seroma or cerebrospinal fluid leak. All patients were followed prospectively in the DBS clinic for adjustments of their stimulation parameters. No patients were lost to follow-up. Treatment of these complications was individualized.

In order to compare the results with those from other centres, a Medline search for appropriate articles using the word "deep brain stimulation" was performed. Additional papers were added following a review of the references.

\section{Surgery}

Surgery was performed in two steps: (i) electrode and (ii) implantable pulse generator (IPG) placement. The electrodes (models 3387-40 and 3389-40 Medtronic, Inc., Minneapolis, MN) were placed under local anesthetic using CT or MRI stereotactic guidance with macrostimulation or microelectrode recording. The scalp was shaved with an electric shaver (not a razor) then prepared with an iodophor brush (Becton Dickinson, Mississauga, ON) followed by two washings with proviodine (Rougier Inc., Chambly, QC).

In Halifax, all scalp incisions were straight. In Vancouver, 50 patients had curvilinear scalp incisions and 40 patients had straight incisions. The first 20 were straight incisions followed by a period of alternating straight and curvilinear incisions and then only curved incisions were used. Straight incisions were centred over the burr hole and approximately three to four centimeters long (see Figure 1). Curvilinear incisions were designed to raise a skin flap such that no portion of the DBS hardware was directly beneath the incision (see Figure 2). Electrodes were secured to the skull using a burr hole ring and cap (Medtronic). All patients received perioperative antibiotics beginning before surgery and continuing for 24 hours using $1 \mathrm{~g}$ cefazolin (Novopharm, Toronto, ON) q8h, or vancomycin $1 \mathrm{~g}$ (Abbott Laboratories, St Laurent, QC) $\mathrm{q} 12 \mathrm{~h}$ if allergic to penicillin.

The second step of surgery (placement of implantable pulse generator) was performed either immediately after the first step or following a trial of stimulation where the electrode was externalized for three to five days (staged procedures). During externalization, patients received intravenous antibiotics. The IPG (models 7424, 7426, 7428, Medtronic Inc.) was placed in a subcutaneous pocket below the clavicle under general anesthetic. This incision was always straight and approximately six centimetres long.

A small third (and rarely fourth incision) was made to facilitate pulling the extension (model 7495 Medtronic Inc.) from the chest to the scalp in a subcutaneous tunnel. A plastic boot was placed over the connector (joining the lead and extension) and tied to exclude fluid. Early in the series, the connector was occasionally close to the mastoid. After two skin erosions in this area, the connector was always pulled to a position under the parietal scalp half way between the scalp incision and the incision behind the ear (see Figure 3). The operative sites were irrigated with normal saline containing Bacitracin 1:10,000 (Pharmacia-Upjohn Inc., Mississauga, ON) and closed with absorbable suture in the galea/subcutaneous and a nonabsorbable suture in the skin. Patients were discharged home the following day after the 24 hour course of intravenous antibiotics.

\section{Statistical comparisons}

All statistical analyses were performed using a computer software package (SPSS advanced statistics, version 8.0;SPSS, Inc., Chicago, IL). Data were analyzed with a nonparametric technique (Pearson chi-square) to determine if externalization prior to implantation was correlated with the infection rate. A similar analysis was performed in the Vancouver patients to determine if the type of incision (straight or curvilinear) correlated with the infection rate. To determine if the length of the procedure correlated with infection rate, cases were ranked in ascending order according to skin-to-skin time, the shortest and longest quartile were then compared for infection rates using Pearson chi-square test. The level of significance was set at the 0.05 level.

\section{RESULTS}

One hundred and forty-four patients (83 male/61 female, with mean age of $56 \pm 16$ years, range 17-82 years) underwent DBS electrode implantation in two Canadian centres between January 1999 and January 2003. There were 77 patients with Parkinson's disease, 27 patients with essential tremor, 18 patients with multiple sclerosis tremor, five patients with post traumatic tremor, 13 patients with dystonia, and four patients with complex facial pain. A total of 203 electrodes were implanted. Ninety-six electrodes were implanted in the thalamus, 35 electrodes were implanted in the globus pallidus, and 72 electrodes were 


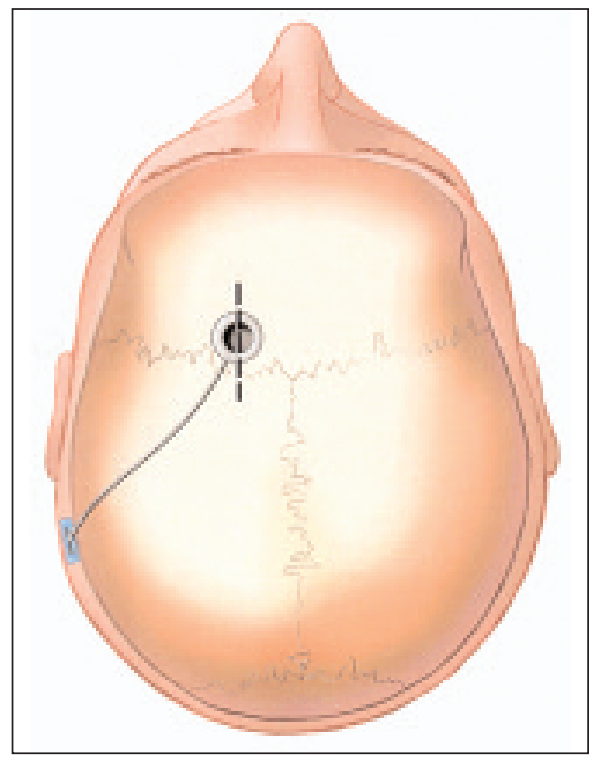

Figure 1: Location of straight scalp incision over DBS lead insertion.

implanted in the subthalamic nucleus. Bilateral DBS surgery, sometimes staged, was performed in 59 patients and unilateral surgery in 85 patients. The average follow-up duration was 24 months (range, 6-60 months). No patients were lost during follow-up.

Postoperative complications are listed in Table 1. Complications related to the DBS hardware were seen in 11 patients (7.6\%). Eight of the 11 patients in this group required an additional surgical intervention to correct the problem.

\section{Infection}

Nine patients $(6 \%)$ developed an incisional infection postoperatively. Three of these resolved with suitable antibiotic therapy and six cases required hardware removal. The infection rate per electrode in this series was $4.4 \%$. The infecting organisms were: staphylococcus aureus in four cases (44\%) and enterobacter in one case $(11 \%)$. In the remaining four cases (44\%) no microorganism was cultured. These cases were assumed to be infections because the incisions initially healed and then later became inflamed with an exudate. The site of infection was the scalp in seven cases and chest in two cases. Early infection (first month) occurred in six of these patients $(67 \%)$ and late infection (after the first month) occurred in the remaining three patients (33\%). The time intervals between DBS implantation and infection were two weeks in one patient, one month in five patients, three months in one patient, seven months in one patient and 14 months in one patient. Predisposing factors such as diabetes, poor nutrition or anemia were identified in four out of nine patients (44\%). Our analysis, however, did not demonstrate any significantly increased incidence of infection in patients with systemic diseases.

There was no significant difference in overall infection rate between the two centres. Patients in Vancouver had two different types of incision. The infection rate was $12.5 \%$ for patients with

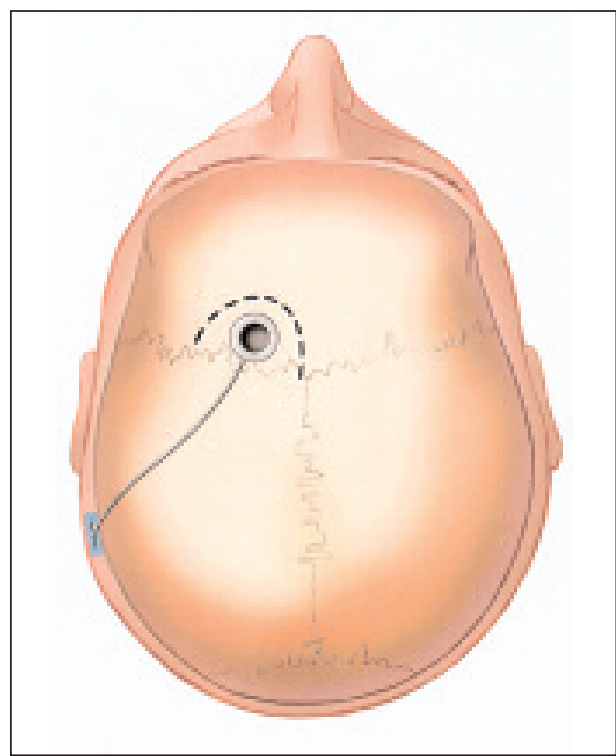

Figure 2: Location of curvilinear scalp incision over DBS lead insertion.

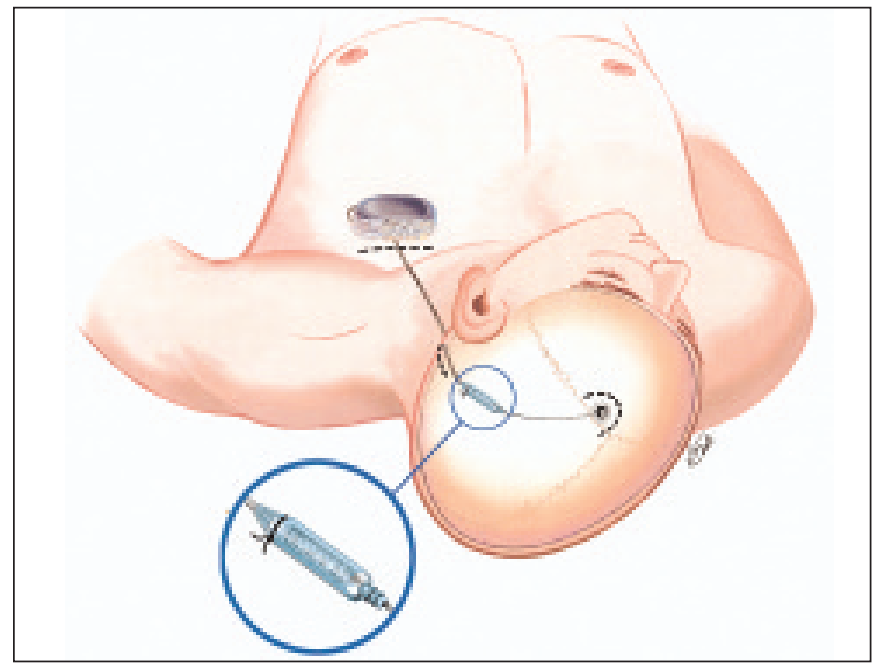

Figure 3: Location of incisions and hardware placement for DBS.

Table 1: Adverse events related to DBS hardware

\begin{tabular}{lccc}
\hline & No of Events & $\begin{array}{c}\text { \% of patients } \\
(\mathbf{n = 1 4 4})\end{array}$ & $\begin{array}{l}\text { \% of electrodes } \\
(\mathbf{n = 2 0 4})\end{array}$ \\
Lead fracture & 2 & 1.4 & 1 \\
Infection & 9 & 6.2 & 4.4 \\
Skin Erosion & $2^{*}$ & 1.4 & 1 \\
IPG malfunction & 0 & 0 & 0 \\
Total adverse events & 13 & $7.6^{*}$ & $5.4^{*}$ \\
\end{tabular}

Total number of adverse events in the current series. * Both patients with erosions also had infections. 
a straight-parasagittal incision and $2 \%$ for patients with a curvilinear incision (Table 2). This more than six fold increase in the rate of infection following a straight incision was statistically significant $(\mathrm{P}<0.03)$. In Halifax, where only straight scalp incisions were used, the rate of infection was 5.6\% (3/54).

For all patients in the study the infection rate was $4.2 \%$ for patients with a one stage procedure and $15.3 \%$ for patients with electrode externalization and a two stage procedure (Table 3 ). We found a significant association, with the greater risk of infection in patients who underwent staged procedures with externalization $(\mathrm{P}<0.003)$. No statistically significant difference in infection rate was found between target sites, length of procedure or for patients who used tobacco.

\section{Fracture of electrodes}

Extension wire fractures occurred in two patients (1.4\%). The fracture rate per electrode was therefore $1 \%$. Both patients noticed sudden loss of the benefits obtained with the stimulation. The fracture was confirmed by radiography in one case and using electrical examination in the other case. The DBS system was reexplored, the fracture site identified in the extension wire, and replaced in both cases.

\section{Skin erosion}

Two patients (1.4\%) experienced erosion of the skin over the lead-extension connector site near the mastoid. The skin erosion rate per electrode was $1 \%$. Both extensions had to be removed. In both cases the resultant infection also involved the lead which was removed as well.

\section{Foreign body reaction}

In this series, no foreign body reaction to the hardware was recognized.

\section{Device malfunction or lead migration}

In this series, none of the implantable pulse generators failed because of technical malfunction. There were no lead migrations.

\section{Discussion}

There are no chronic device related complications following pallidotomy or thalamotomy. The theoretical advantages of DBS (reversibility, titration of clinical benefits, reduced permanent side-effects) must therefore be weighed against the inherent risk of device related complications. Device related complications are well-reported but range dramatically between series $(6 \%$ to $28.5 \%$ of patients). One source for this variability may be the era in which the surgery was performed. Early series reported hardware related adverse event rates of $24 \%$ per patient. ${ }^{4}$ More recent series report rates from $6-9 \%$ per patient. ${ }^{5-8}$ This may reflect improved hardware technology and surgical experience. In our series, the overall adverse effect per patient due to hardware problems was $7.6 \%$. Our analysis suggests that this rate may be lowered further with appropriate surgical techniques. The types of hardware related problems fall into several categories: infection, skin erosion, lead migration or fracture, system malfunction and rare problems such as foreign body reactions. These problems have been recognized since the early series dealing with chronic electrode implants for pain. ${ }^{9}$

Infection rates in recent DBS series range from 0 to $10.6 \%$ per
Table 2: Type of incision and infection rate

\begin{tabular}{lcccc}
\hline Incision & No. of Patients & Infection & rate $(\%)$ & $\mathbf{X}^{\mathbf{2}}$ \\
Straight & 40 & 5 & 12.5 & 0.03 \\
Curvilinear & 50 & 1 & 2 &
\end{tabular}

In the subgroup of patients from Vancouver (who had both types of incisions) the infection rate was higher in those with a straight scalp incision compared to those with a curvilinear incision.

Table 3: Stimulation trial and infection rate

\begin{tabular}{lcccc}
\hline Procedure & Patients (leads) & Infection & rate $(\%)$ & $\mathbf{X}^{2}$ \\
One stage & $118(166)$ & 5 & 4.2 & 0.003 \\
Externalization & $26(37)$ & 4 & 15.3 &
\end{tabular}

Patients who had a trial of externalization had a higher infection rate than those who had a one-stage procedure.

Table 4: Attempted non surgical treatment of infection following DBS surgery

\begin{tabular}{|c|c|c|}
\hline Series & Cases of Infection & $\begin{array}{l}\text { Success with } \\
\text { antibiotics alone }\end{array}$ \\
\hline Oh et $\mathrm{al}^{15}$ & 6 & $1(17 \%)$ \\
\hline Kumar et $\mathrm{al}^{21}$ & 4 & $3(75 \%)$ \\
\hline DBS study group ${ }^{17}$ & 4 & $2(50 \%)$ \\
\hline Levy et $\mathrm{al}^{4}$ & 23 & $1(4 \%)$ \\
\hline Koller et $\mathrm{al}^{3}$ & 2 & $2(100 \%)$ \\
\hline Present study & 9 & $3(33 \%)$ \\
\hline
\end{tabular}

Incision infections after DBS surgery have occasionally been successfully treated without explantation of the device.

electrode. ${ }^{1,5,6,10-19}$ The period of time between implantation and infection is rarely longer than eight months. ${ }^{4,20}$ A previous study found no difference in the frequency of infection during the early (less than one month) and later (after one month) postoperative period. ${ }^{4}$ The causative organisms most often implicated in DBS hardware infections are: staphylococcus (epidermidis and aureus), enterobacter, streptococcus, pseudomonas and rarely mycobacterium or candida.4,15,20 Deep brain stimulation infections can be divided into two types. First, external infections which begin as erythema or healing problems of the surgical site. This type of infection usually does not give rise to fever or meningitis. Causative bacteria are usually from the patient's skin flora. Second, internal infections due to hematogenous spread of bacteria to the hardware. This is rare but may be the cause of meningitis or intracranial abscess. ${ }^{4,20}$

There is no general consensus when an infected DBS system 
Table 5: Reported rates of DBS hardware related complications

\begin{tabular}{|c|c|c|c|c|c|c|c|}
\hline Study & $\begin{array}{l}\text { Patients/ } \\
\text { electrodes }\end{array}$ & $\begin{array}{l}\text { Infection per } \\
\text { electrode \% }\end{array}$ & $\begin{array}{l}\text { Erosion per } \\
\text { electrode \% }\end{array}$ & $\begin{array}{l}\text { Migration per } \\
\text { electrode } \%\end{array}$ & $\begin{array}{l}\text { Electrode fracture- } \\
\text { malfunction } \%\end{array}$ & $\begin{array}{c}\text { Overall adverse } \\
\text { events per patient \% }\end{array}$ & $\begin{array}{c}\text { Additional } \\
\text { procedures \% }\end{array}$ \\
\hline Levy $^{4}$ & $141 / 304$ & 7.5 & 3.3 & 6.6 & 6.6 & 24 & na \\
\hline Kumar $^{21}$ & $68 / 74$ & 5.4 & na & na & 5.8 & 13.2 & 8.8 \\
\hline Bendok $* * 9$ & 649 / na & $3.3-13.3$ & 1.8 & $2-9.9$ & $5-13.3$ & na & na \\
\hline Limousin $^{8}$ & $110 / 135$ & 1.5 & 0.7 & 4.5 & na & 9 & 8 \\
\hline Benabid $^{10}$ & $197 / 316$ & 0.9 & 1.6 & na & 1.3 & 7.7 & na \\
\hline Schuurman ${ }^{16}$ & $34 / 51$ & 2 & na & na & na & 6 & na \\
\hline Beric $^{11}$ & $86 / 149$ & 0.7 & na & na & 2 & 11.6 & 9.3 \\
\hline DBS study group ${ }^{17}$ & $134 / 268$ & 2.7 & 0.4 & 3.7 & 2.2 & 11.9 & na \\
\hline Koller $^{12}$ & $49 / 49$ & 2 & 6.1 & 2 & 18 & 28.5 & 14.3 \\
\hline Lyons ${ }^{14}$ & $206 / 275$ & 5.5 & na & na & na & $65^{*}$ & na \\
\hline Joint $^{24}$ & $39 / 79$ & 0 & 1.2 & 0 & $5-10$ & 20 & 15.8 \\
\hline Kondziolka $^{13}$ & $66 / 66$ & 10.6 & 3 & 1.5 & 15 & 27 & 33.3 \\
\hline $\mathrm{Oh}^{15}$ & $79 / 124$ & 9.7 & na & 5.1 & 5.1 & 25 & 36.7 \\
\hline Pollak $^{5}$ & $300 / 515$ & 1.9 (and erosion) & & na & 1.4 & 7.3 & 7.3 \\
\hline Vingerhoets ${ }^{19}$ & $50 / 100$ & 1 & 1 & na & 8 & na & na \\
\hline Present study & $144 / 204$ & 4.4 & 1 & 0 & 1.4 & 9 & 7 \\
\hline
\end{tabular}

Reported rates of complications in the literature. na $=$ not available, *not clear if it is only hardware related complications, **meta-analysis with eight studies including complications rate

must be removed. A review of the literature supports an initial attempt at conservative treatment with antibiotics (Table 4). Incision infections above DBS electrodes have resolved with suitable antibiotic therapy alone..$^{3,4,15,17,21}$ Unfortunately, this is not always enough. Removal of an involved electrode or generator while leaving uninvolved electrodes and hardware in place may be required. ${ }^{4,18,22}$ Occasionally all the hardware must be removed to allow the infection to heal. There is also no consensus about the duration of antibiotic treatment before considering device removal. Our practice is to remove the DBS device if the infection persists longer than one month.

Previous studies found no correlation between the time of electrode externalization and the occurrence of infection, but a direct comparison of infection incidence with electrodes, externalized or not, has never been made. ${ }^{4,15}$ In our series, we found a significant association, with a greater risk of infection in patients who underwent a second stage procedure (temporary externalization of the lead) compared to those patients who had no externalization. We have, therefore, not utilized externalization trials except in rare cases such as for the treatment of pain. If externalization is required, there is no consensus about whether to give prophylactic antibiotics during the trial. ${ }^{6,12}$

The role of the type of scalp incision (curvilinear or straight) has not been previously investigated. In our series, patients who underwent surgery in Vancouver had both types of incision and could be directly compared with a minimum of variability. Those with straight incisions were six times $(\mathrm{P}<0.03)$ more likely to develop an infection. The curvilinear incision is designed to avoid placing the hardware directly beneath the incision. It is common practice and well-accepted in cerebrospinal fluid shunt procedures. Placing the valve system and tubing away from the incision and closing in layers can reduce the incidence of skin breakdown and infection. ${ }^{23}$ It seems reasonable to extrapolate this large experience with shunt implants to our patients with DBS implants. The infection rate in the Vancouver patients with straight incisions (12\%) and curved incisions (2\%) may have been biased by a learning curve. We began with straight incisions; then after twenty patients made alternating straight and curved incisions, and finally performed only curved incisions. A prospective, randomized trial would be required to definitively conclude whether incision type influences infection rate.

The length of surgery did not correlate with infection rate. There was no significant difference in the infection rate for the quartile of patients who received the longest operations compared to the quartile who received the shortest. Our operative times ranged from 100 to 600 minutes and were similar to previous published studies. ${ }^{15,24}$

Skin erosion is a common problem in DBS series and has been reported to range between $0.4 \%$ and $6 \%$ (Table 5). If the subcutaneous pocket receiving the pulse generator at the time of the initial implantation is too small for the device, undue tension on the overlying skin may cause gradual erosion. Erosion of the skin may also occur over the connector site or in the scalp incision when bulky hardware is implanted..$^{4,6,15,18}$ We placed the connector high up under the parietal scalp well-away from the potentially mobile area near the mastoid. The connector is placed halfway between the scalp incision and the incision behind the ear (see Figure 3). Both skin erosions in our series occurred over connectors placed too inferiorly near the mastoid. There is now a new connector (model 7482, Medtronic), with a lower profile that may help to reduce skin erosions.

Migration of the electrode from the target occurs if the electrode is poorly attached to the burr hole. In early series, electrode migration occurred in up to $14 \%$ of cases..$^{9,21}$ More recent series have quoted an incidence of electrode dislodgement from $0 \%$ to $5.1 \% .^{6,12,13,15,17-19,24,25}$ Various methods have been 
developed to secure the DBS electrodes to the calvaria. ${ }^{13,26,27} \mathrm{We}$ used the silicone burr hole ring and cap, which is supplied by the electrode manufacturer (Medtronic). We did not encounter this problem in our series of 204 electrodes. Other centres use bone cement or miniplates to secure the lead electrode. ${ }^{26}$ No study has compared these techniques.

Electrode fracture or malfunction may occur if the connector screws are overtightened or if the connection between electrode and cable is subjected to excessive movement such as in the neck below the mastoid. ${ }^{22}$ The wires in the electrode are made of platinum and can easily be crushed by the screws. Any point of the electrode subjected to stretching or crushing is susceptible to these complications, but most fractures occur in the lead near the connection between the lead and extension. A fracture is suspected when a patient realizes that the stimulation is not working properly and the benefits of the surgery disappear suddenly. The electrical examination of the system reveals elevated electrode impedance ( $>2000 \mathrm{Ohms}$ ) with low system current $(<7 \mu \mathrm{Amp})$. The diagnosis can be confirmed by radiography. Some authors have reported that dynamic radiography (with the head turned) may be needed to demonstrate the disrupted electrodes. ${ }^{28}$ The incidence of electrode fracture or malfunction ranges from $0 \%$ to $13.3 \%$ per patient among the reported series.,9-12,14,15,17-19,21,24 We recommend placing the vulnerable connection between lead and extension under the parietal scalp, as this location prevents the connection from moving. The mobility of the neck may be better tolerated by the extension because its wires are made of steel. Medtronic has recently included a torque wrench with its extension kit to prevent over tightening at the lead-extension connection.

Another reported problem, but not seen in this series, is electrode short circuit and intermittent function due to the presence of fluid within the boot over the connector. We tie over the boot to deliberately exclude fluid from the connection. Electrode short circuit would be suspected with loss of clinical benefit and low electrode impedance and high current.

A foreign body reaction manifesting as inflammation and local pain around the operative site was reported in $1 \%$ to $1.6 \%$ per electrode in chronic pain series. ${ }^{4,9}$ Removal of the DBS equipment was necessary in almost all patients. In the past, the use of cyanoacrylate glue to fix the electrode to the burr hole ring may have been partly responsible for the formation of granulomas. $^{29}$

Chest wound hematoma or seroma is a relatively rare complication. Usually they are managed conservatively unless expanding in size, tense or very painful. Minor wound pain is expected after device implantation, almost always controlled with simple analgesics and settles quickly. Continuing pain may eventually manifest as an obvious infection.

This study was not randomized or blinded and was thus vulnerable to bias. The findings cannot exclude the possibility that other factors such as different hospital conditions or surgeon experience could have contributed to the results. The results showed a strong correlation with incision type or externalization and infection rate. This does not prove causation. Finally, the average length of follow-up per patient in our series was 24 months (range 6-60 months). A longer follow-up may be necessary to assess the long term reliability of DBS hardware.
Hardware related complications were not common. A period of externalization of the electrodes for a stimulation trial was associated with an increased infection rate. It is also possible that a straight scalp incision instead of curvilinear incision may also lead to an increase in the rate of infection. With a clear understanding of the accepted DBS device indications and their potential complications, patients may make a truly informed decision about DBS technology.

\section{REFERENCES}

1. Benabid AL, Pollak P, Gervason C, et al. Long term suppression of tremor by chronic stimulation of the ventral intermediate thalamic nucleus. Lancet 1991; 337: 403-406.

2. Benabid AL, Pollak P, Gao D, et al. Chronic electrical stimulation of the ventralis intermedius nucleus of the thalamus as a treatment of movement disorders. J Neurosurgery 1996; 84: 203-214.

3. Koller W, Pawha R, Busenbark K, et al. High-frequency unilateral thalamic stimulation in the treatment of essential and parkinsonian tremor. Ann Neurol 1997; 42: 292-299.

4. Levy R, Lamb S, Adams J. Treatment of chronic pain by deep brain stimulation: Long term follow up and review of the literature. Neurosurgery 1987; 21: 885-893.

5. Pollak P, Fraix V, Krack P. et al: Treatment results. Parkinson's disease. Mov Disord 2002; 17(Suppl 3): 75-83.

6. Hariz MI. Complications of deep brain stimulation surgery. Mov Disord 2002; 17(Suppl 3): 162-166.

7. Hariz MI, Shamsgovara P, Johanson F, Hariz G, Fodstad H. Tolerance and tremor rebound following long term chronic thalamic stimulation for parkinsonian and essential tremor. Stereotact Funct Neurosurg 1999; 72: 208-218.

8. Limousin P, Speelman D, Gielen F, et al. Multicentre European study of thalamic stimulation in parkinsonian and essential tremor. J Neurol Neurosurg Psychiatry 1999; 66: 289-296.

9. Bendok B, Levy R. Brain stimulation for persistent pain management. In: Gildenberg P, Tasker P (Eds). Textbook of Stereotactic and Functional Neurosurgery. New York: McGrawHill, Inc., 1998: 1539-1546.

10. Benabid AL, Koudsie A, Benazzouz A. Subthalamic nucleus deep brain stimulation. In: Lozano AM (Ed). Movement Disorders Surgery. Progress in Neurological Surgery. Basel: Karger, 2000: 196-226.

11. Beric A, Kelly PJ, Rezai A, et al. Complications of deep brain stimulation surgery. Stereotact Funct Neurosurg 2001; 77: 73-78.

12. Koller WC, Lyons KE, Wilkinson SB, et al. Long term safety and efficacy of unilateral deep brain stimulation of the thalamus in essential tremor. Mov Disord 2001; 16: 464-468.

13. Kondziolka D, Whiting D, Germanwala A, et al. Hardware-related complications after placement of thalamic deep brain stimulator systems. Stereotact Funct Neurosurg 2002; 79: 228-233.

14. Lyons KE, Koller WC, Wilkinson SB, et al. Surgical and devicerelated events with deep brain stimulation (abstract). Neurology 2001; 56(Suppl 3): A146.

15. Oh MY, Abosch A, Kim SH, et al. Long term hardware-related complications of deep brain stimulation. Neurosurgery 2002; 50: 1268-1276.

16. Schuurman RP, Bosch A, Bossuyt P, et al. A comparison of continuous thalamic stimulation and thalamotomy for suppression of severe tremor. N Engl J Med 2000; 342: 461-467.

17. The Deep Brain Stimulation for Parkinson's Disease Study Group. Deep brain stimulation of the subthalamic nucleus or the pars interna of the globus pallidus in parkinson's disease. N Engl J Med 2001; 345: 956-963.

18. Umemura A, Jaggi LJ, Hurtig IH, et al. Deep brain stimulation for movement disorders: morbidity and mortality in 109 patients. J Neurosurg 2003; 98: 779-784.

19. Vingerhoets FJ, Russmann H, Pollo C, et al. Results and adverse events in 50 consecutive patients treated by STN-DBS. Mov Disord 2002; 17(Suppl 5): P666.

20. Merello M, Gammarota A, Leiguarda R, et al. Delayed intracerebral 
electrode infection after bilateral STN implantation for Parkinson's disease. Mov Disord 2001; 16: 168-170.

21. Kumar K, Toth C, Nath R. Deep brain stimulation for intractable pain: a 15-year experience. Neurosurgery 1997; 40: 736-747.

22. Schwalb JM, Riina HA, Skolnick B, et al. Revision of deep brain stimulation for tremor. Technical note. J Neurosurg 2001, 94: 1010-1012.

23. Di Rocco C, Iannell A. Complications of CSF shunting. In: Di Rocco C (Ed). The Treatment of Infantile Hydrocephalus. Boca Raton: CRC Press Inc., 1987: 79-153.

24. Joint C, Nandi D, Parkin S, et al. Hardware-related problems of deep brain stimulation. Mov Disord 2002; 17(Suppl 3): 175-180.

25. Pahwa R, Lyons KE, Wilkinson SB, et al. One-year follow-up of bilateral subthalamic stimulation in Parkinson's disease.
Neurology 2001; 56(Suppl 1): A146.

26. Favre J, Taha JM, Steel T, et al. Anchoring of deep brain stimulation electrodes using a microplate. Technical note. J Neurosurg 1996; 85: 1181-1183.

27. Ray CD. Burr-hole ring-cup and electrode anchoring device. Technical note. J Neurosurg 1981; 55: 1004-1006.

28. Mohit A, Samii A, Slimp JC, et al. Mechanical failure of the electrode wire in deep brain stimulation (abstract). Mov Disord 2002; 17(Supp15): 648.

29. Jimenez JC, Salazar PM, Finocchio JA, et al. STN -DBS complicated with cyanoacrylate granullomas and secondary staphylococcal infection. Mov Disord 2002; 17(Suppl 5): 673. 